\title{
ACUTE POLYMORPHOUS PSYCHOTIC DISORDER. EVOLUTIONARY POSSIBILITIES
}

\author{
Simona Trifu ${ }^{1}$, Alexandra Popescu ${ }^{2}, \&$ Eduard George Carp ${ }^{3}$ \\ ${ }^{1}$ University of Medicine and Pharmacy "Carol Davila”, Bucharest (Romania) \\ ${ }^{2}$ Hospital for Psychiatry “Alex. Obregia”, Bucharest (Romania) \\ ${ }^{3}$ Hospital for Psychiatry Sapunari (Romania)
}

\begin{abstract}
Motivation: psychotic confusion is often a psychiatric emergency encountered in several mental disorders, making it difficult to distinguish between a major depressive episode that overlaps perceptual distortions and delirious ideation, and an acute psychotic episode that risks developing into schizophrenia. A meticulous psychiatric interview performed after the remission of the psychotic phenomenology, bearing in mind the chronology of events and the fine analysis of the dispositional changes dictate the evolution and prognosis.

Objectives: we aim to highlight the functioning mechanisms and the therapeutic response of a 27 -year-old female patient, admitted for an acute polymorphic psychotic episode, who presented schizophrenic symptoms, developed on a paranoid-narcissistic personality structure. The existence of rejection sensitivity prior to this episode calls for a differential diagnosis with a depressive episode of psychotic intensity, which gives rise to the opportunity of treatment with antidepressants, with careful consideration of the potential effect on the current psychotic episode.

Methods: emergency psychiatric hospitalization, medical surveillance, injectable antipsychotic administration due to negative symptoms and food refusal, daily psychiatric monitoring, EEG, cerebral MRI, psychological evaluation, psychodynamic interview, supportive psychotherapy for self-help.

Results: in the construction of the patient's diathesis, we identify early abandonment and change of attachment figure, personality traits from the narcissistic registry, fragility of the ego, sensitivity. Premorbid, uses defense mechanisms such as denial, repulsion, and vice versa. At the beginning of a young adult's life, the patient encounters a few failures in the workplace as well as in private life, which has changed his mood in the depressed sense over the past 6 months, the patient refusing SSRI type anti-depressives and psychotherapy. Later on, hallucinations and auditory pseudo-hallucinations, delusional preoccupation concerns centered on body function, and the idea of maintaining body image, the somatic delirium sketch, with bizarre behavioral changes, stereotypes and postures, in the last days before admission overwhelming food negativity and psychotic confusion. The rapid cutback of the episode is done with the classic injectable neuroleptic with subsequent passage on Aripirazole and the re-evaluation of the depressive component for the choice of the dual antidepressant SSRI.

Conclusions: the paranoid-narcissistic personality structure and the prevalence of denial mechanisms dictated the diagnosis of polymorphic psychotic disorder, wherein the central concerns are of a somatic nature, necessitating antidepressants and being post psychotic. There was an unfavorable response to the SSRI (Sertraline) which led to the psychotic distress becoming more intense. The treatment with dual AD (Mirtazapine) ultimately gave a positive result.
\end{abstract}

Keywords: Polymorphous psychotic disorder, somatic delirium, psychotic denial, paranoid-narcissistic personality structure.

\section{Patient history}

Patient D., a 27-year-old girl, graduate of the Law School, at a leading university, has passed the entrance examination at the Bar of Law after the fourth attempt. She is currently working at a law firm, where, she says, she is overwhelmed by the amount of work and unsatisfied with the lack of immediate rewards. His parents were preoccupied of their personal careers, working in diplomacy and being attached to various embassies for long periods of time, being distant for the patient both physically and emotionally. The patient grew up with her grandparents until the age of eight, and at 17, her parents 
re-established themselves in Belgium, where D. was unable to integrate socially, returning alone to the country.

About his current social relationships, the patient claims he only has superficial friendships ("My colleagues have always been jealous of me, they always wanted to sabotage me through the advice they gave me."). She had sex with a faculty colleague, of whom she fell in love, a unidirectional feeling, present today even though she had no contact for three years.

\section{Disease history}

Depressive symptomatology started three months prior to admission, the patient had two ambulatory visits during this period. By not complying with the recommended medical treatment, his mental condition worsens, reaching a psychotic rank.

\section{Examination of psychic state}

\subsection{Observations}

The patient, in relatively unkempt condition, a state of inner disorder found in clothing, intrapsychic tension, temporo-spatial disorientation and personal life history, confusion, psychomotor unrest; rises in the cabinet several times, looks in the mirror, with a gesture in which he tries to reposition his jaw, a blank look, a facies flattened, tics present in the form of convulsions in the limbs and the body, grimaces incongruent with mood and concord with the world indoor. (Kernberg 1995)

\subsection{Perception}

She has hallucinations and pseudo-hallucinations, predominantly proprioceptive but also auditory, the presence of voices being suggested by bizarre psychotic behavioral changes of perplexity and emphatic mutant changes. Relate later how the content of the voices is an encouragement; possibly in the past, the presence of positive auditory hallucinations with negative reference to the patient's inability and incapacity (Cassidy \& Shaver, 2016). Body pattern disruptions, mainly at the face, punctuated by small ophthalmic defects, as well as oral-maxillo-facial corrections by previous interventions and presently fixation points, in which the patient presents cenesthopathies and subsequently qualitative perception disorders. (Cournut, 1991)

\subsection{Attention}

Attention Deficit Disability, which generates perplexity, as well as increased latency in responses. Psychotic confusion due to difficulty switching in the concentrated focus field. (Scheffer, 2004)

\subsection{Memory}

She presents hypomnesia, with hypermnesia for some delusional integrated pseudomonas.

\subsection{Thinking}

Hypochondriac delusional ideation, mainly centered on altering the body's scheme, on minimal defects and persistent beliefs in the need to modify them; functioning on the projection mechanism, psychotic denial of the undesirable aspects of reality, reversal of the effect with the cause, easy skating between the concrete and the metaphorical plane, need of narcissistic mirroring, mentality deficit, magical belief according to which the external reality imprints the internal.

\subsection{Affectivity}

It refers to a major depressive mood several months ago, lived for a short duration, then denied. (Kohut, 2009) The patient clears from the depressed side by itself, experiencing the emphatic self-sufficiency delusion, with a later hypochondriacal turn, with a return to primary narcissism and the importance of body needs. Affective inversion towards parents.

\subsection{Activity}

Activity is characterized by the presence of attitudes and postures, grimaces and tics, in which the symbolism of delusional ideas is represented in the act. Verbal, nutritional and physiological negative at admission. Regression to early behaviors. (Freud, 2014) 


\title{
3.8. Personality
}

Psychotic anguish of destruction of her Ego.

\subsection{The consciousness of the disease}

\author{
Absent.
}

\section{Patient evolution}

During the meetings, D. presents encounters in which he behaves neurotic, in a psychotic continuum. We identify the early traumas of the separation and the defense mechanisms in which the house and the country become shields of resistance ("I wanted to be closer to what I felt at home. My parents ... I did not represent them as my home... "). The second shield of resistance becomes work, along with narcissistic mechanisms to strengthen the Ego ("I wanted to be able to progress professionally, to be the best in everything. I always told myself I could do more!"). Her labor of habituation with loneliness is narcissistic, the excessive use of suppression causing the formation of a repressed, which in adult life turns aggressively towards itself in the form of the delusional hypochondriac idea of the major depressive episode. (Roussillon, 2011)

Manifestly, the trigger for the current episode is isolation and intense intellectual effort for the Bar entrance examination, held for the fourth time ("I isolated myself to learn, I refused to go out, I slept, I ate, and I learned"). Latently, the trigger is a failing pseudo-relationship with a narcissistic invisible man, with whom D. had sex occasionally three times and admires him with the conviction that he should know the feelings she carries. In relation to this man, the patient slides into a trap: "Let me cover myself to show that I can. I could not tell him how I felt. " The girlfriends refuse to be "relatives" between her and this man and retreat feeling too much pressure on D.

The current episode starts right after entering Law Bar and starting the job as a trainee lawyer, the patient trying to deny his sad disposition, despair, insecurity and self-esteem (Krumwiede, 2014): "I was sad since I start working, I was coming home crying that I was not well seen by the rest of the world. I felt the need for help, I wanted to talk to someone, to say that I'm not afraid of being kicked out because I do not know everything". As an elaboration attempt, her mother is calling for a meeting. In the tumult of the afflictions revealed in the blast of crying, the mother puts funny pictures on the phone, refuses any negative thought coming from D. and the only statement he can make is: "If you continue like this, you will not get well."

Concretely, D.'s parents return to the country, which the patient interprets as a violation of the borders as a moment of intrusion, breaking his protective barriers: "My mother settled in the living room and invaded my space. Before that, I could not say that something bothers me, and now I came to write them to tell them that I want to remain alone".

After the change of mood in depressive way, the hypochondria concerns appears, the delusional beliefs related to the perception of the body's scheme, along with the hallucinations and pseudo-hallucinations of the hearing, meant to cancel the depression (Gide, 2001) appear: "The voice I was hearing was my internal intellect, what I thought was well to say, I have no problem and I will go over. " The delusional idea develops on pseudo-reminiscences related to anterior oral-maxillo-facial interventions with a corrective role, as well as ophthalmic correction of dioptric vision, D. being an inclined beard to sustain its image mainly on the physical side. Thus, any attack on his bodily health is profoundly psychologically disturbing (Adler, 2010). The delusional ideas are based on anxiety of non-self-indulgence and non-recognition of feelings, along with the easy glide between the metaphorical plane and the concrete one: "I made myself a certain image in the faculty, and now I was looking in the mirror, I was more admired. I feared myself because I could not figure out what I was looking at. "

At the admission, D. presents quasi-continuous psychotic-altered behaviors in which he looked in the mirror, repositioned his jaw, adopted bizarre physiognomies and positions, which he later described as having a role to reduce psychotic anxiety: "I was looking in the mirror to confirm that I look like the one in my mind". Mirroring is a primitive narcissism-paranoiac mechanism in which the external reality is positioned as true before the internal reality, imposing it (Gabbard, 2014): "I was not able to make my own personality. I took part of the good things of men"," Can I hear voices in my ears? I wanted to hear their voices! It was a dark nightmare - shadows. The voices told me to shut up".

The peculiarity of this case is represented by proprioceptive hallucinations on which the hypochondrial delusion originates in the fragility of self-image (Williams \& Gabbard, 2007). In another, we note the perpetual effort to maintain the narcissistic boundaries of the Ego in the absence of the parental mirror mechanism ("I was trying to repress myself, to make them proud"). Transgression depression - delirium arises from inability mother containment suffering daughter when, metaphorically speaking, it did not break the soul, but jaw (Winnicott, 2005): "When I complained, the effort that a lot, 
my jaw went down. Then my face took the form of crying. That's why I looked sad in the hospital. I was depressed for what I was looking at. I felt like I needed someone in a way that I had not felt before", " I behaved like this because I refused to think I was in the hospital. I did not want to know I was there; I did not want to know I was so bad. "

Self-defense systems developed by the patient in recent months have registered in the psychotic area, with behavior change in a bizarre way and regression to baby's age (refuses to go to the toilet, unable to function excretory than the tub full of water: "It happened to me because they came over me!"). Tics and grimaces are interpreted as symbolic moments of solitude with himself: "I was in a crisis and I was walking alone in the house, thinking what to do. There were moments of focus, not tics. It was my way of struggling with being in the hospital". The mechanism of denial of reality functioned in a cleaved manner until the patient was in love: "I cannot deny the reality of others, I can only deny mine". Love is a land on which D. does not step, choosing unconsciously for the hypochondriac delirium and not the erotic one. (Klein, 2011)

\section{Treatment}

Throughout hospitalization, the patient was treated with a combination of antipsychotic (Aripiprazole $30 \mathrm{mg}$ ) and two antidepressants (Mirzaten $30 \mathrm{mg}+$ Sertraline $100 \mathrm{mg}$ ) along with benzodiazepines. Under this medication, reduced psychotic dimension was observed, with the cancellation of denial and the promise of continuing outpatient treatment. The treatment schedule was also recommended at home, with monthly psychiatric monitoring and psychotherapy sessions. Once discharged, the patient accuses multiple adverse reactions to psychiatric treatment and threatens replacement of drugs with a natural approach, it is found the reinstatement of somatic delirium. For the risk of non-compliance, Flupentixol $20 \mathrm{mg}$, twice intramuscular injection is recommended. Also, it is chosen to remove the SSRI (Sertraline) from the treatment scheme, as it is observed that hypochondriac phenomenology is under this drug.

\section{References}

Adler, A (2010). Understanding Human Nature. Eastford: Martino Fine Books; Tra edition. Cassidy, J. \& Shaver, P. (2016). Handbook of Attachment, Third Edition: Theory, Research, and Clinical Applications. New York: The Guilford Press.

Cournut, J (1991). L'ordinaire de la passion: Névroses du trop, névroses du vide (Le Fil rouge) (French Edition). Paris: Presses universitaires de France.

Freud, S (2014). Sigmund Freud 7 book premium collection: General Introduction to Psychoanalysis; Totem and Taboo: Interpretation of Dreams; Dream Psychology; and many more (Timeless Wisdom Collection 626) Kindle Edition. Business and Leadership Publishing.

Gabbard, G (2014). Tratat de psihiatrie psihodinamica. Bucuresti : Editura Trei.

Gide, A (2001). If it dies ... an autobiography. New York: Vintage.

Kernberg, O (1995). Borderline Conditions and Pathological Narcissism (The Master Work Series). Lanham: Jason Aronson, Inc.

Klein, M (2011). Love, Guilt and Reparation Kindle Edition. New York: Vintage.

Krumwiede, A (2014). Attachment Theory According to John Bowlby and Mary Ainsworth. Munchen: GRIN Publishing.

Kohut, H (2009). The Analysis of the Self: A Systematic Approach to the Psychoanalytic Treatment of Narcissistic Personality Disorders. Chicago: The University of Chicago Press.

Roussillon, R (2011). Primitive Agony and Symbolization (IPA: Psychoanalytic Ideas and Applications). London: Karnac Books ltd.

Scheffer, M (2004). Keys to the Soul: A Workbook for Self-Diagnosis Using the Bach Flowers. Ashingdon: C.W. Daniel Company ltd.

Williams, P \& Gabbard, G (2007). Key Papers in Literature and Psychoanalysis (The IJPA Key Papers Series). New York: Karnac Books.

Winnicott, D.W. (2005). Spaima de prabusire - Explorari psihanlitice. Bucuresti: Editura Fundatiei Generatia. 